\title{
Flowdrilling: a Preliminary Analysis of a New Bush-Making Operation
}

\author{
A. H. Streppel, Twente University of Technology; H. J. J. Kals, Twente University of Technology (1)
}

\begin{abstract}
Flowdrilling is a bush-making operation applied to thin walled products for joint engagenent. Fastenings exhibit aechanical properties which depend largely on the shear strength of the parent material and the area of engagenent. Flowdrilling is specifically designed to increase the latter. Jevelopwents during the last six or seven years have resulted in a number of industrial usefull applications. Previous attempts to use "rotary plunging methods" failed due to low tool life and the inability to obtain an acceptate finish. The paper describes the different process variables and gives the results of a prelininary analysis of the different mecharical and physical aspects. Manufacturing properties like cycle time and tool life are also dealt with.
\end{abstract}

INTRODUCTION

Flow-drilling is a bush-making process applied to thin walled products for joint engagement (thread tapping, thread rolling, hard and soft soldering and the use of adhesives). [1][5] Contrary to conventional drilling, in flow-drilling there is no naterial removal but a displacement of materlal. The bush is formed from the parent material which is subjected to friction heating, but at the end the bush naterial has a finer structure because of the occurrence of dynamic recrystallization.

Figure IA shows the typical shape of a flow-drilling tool, having a specially shaped conical nose. In general the shape of the flow-drill can be divided into 5 sections:

1. The tip

2. The conic part (top-angle about $35^{\circ}$ )

3. The calibration (cylindric) part

4. The collar

5. The shank

CROSS-SECTION A-A
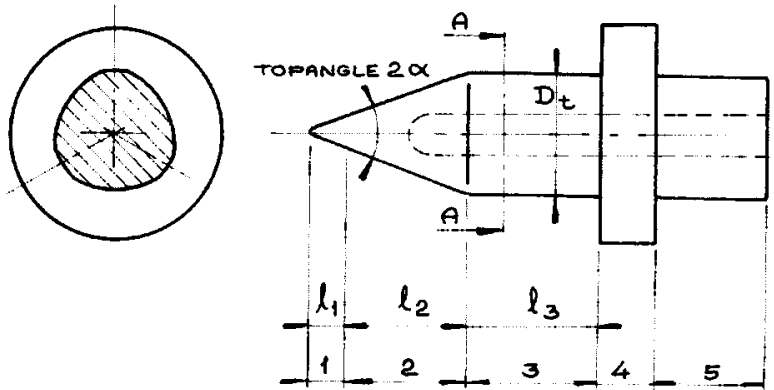

Figure LA: Typical shape of a flow-drilling cool.

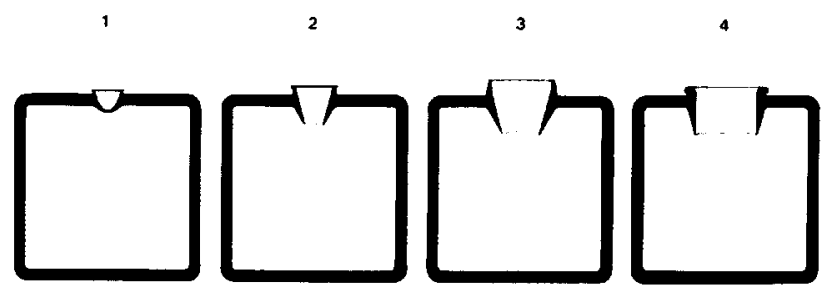

Figure IB: Four stages in the forming of a bush.

The presently available tools are made of cemented carbide (P25P35) covering diameters from $3 \mathrm{~mm}$ to about $30 \mathrm{~mm}$.

Both the conical and the calibration part are provided with 3 or 4 facets (see fig. $1 \mathrm{~A}$, cross-section $A A$ ) to promote local Eriction heating while preventing sticking. Tools above $10 \mathrm{~mm}$ diamecer are provided with a boring $\left(0,6 \times 0_{\mathrm{t}}\right)$ to prevent nupture
by thermo- shock.
Flow-drilling is an operation controlled by friction heating. Starting from an initial indentation, and under the influence of a constant axial pressure, the heated metal of the workplece is extruded both upwards and downwards in the ratio of about. $40 \%$ to $60 \%$ respectively. The height of the so-formed bush measures 2.5 to 3 times the original thickness of the material. Due to local friction heating of the workpiece, the operation can be performed with a relatively small axial pressure, so that there is no need for special measures to support blind sections. Flowdritiling requires the use of a high-temperature resistant dribing requires the use of a high-temperature resistant Lubricant, (MolykoteHTD and -HTF) sparingly applied to the tool
to prevent sticking, which is detrimental to surface quality and tool life (vibrations).

The main area of application is in the manufacture of manifolds tor air, gas or liquid and direct fastenings in metal furniture, donestic products and in the electric and electronic industry. A flow-drilled bush can be used as a seal for plain bearings in a wide range of nachinery, and even can itself act as a bearing surface.

plow-drilling can be applied to a wide variety of materials like Plow-drilling can be applied to a wide variety of materials like
different carbon steels, stainless steel, copper, brass and aluminium. Difficulties arise for strong pre-strainhardened qualities, which, in particular in the case of aluminium, results in a bad quality of the bush.

The advantages of flow-drilling compared to other methods of making fixing bushes are the following [4][6]:

Flow-drilling is a single cycle operation suited for automated manufacturing production.

Because there is no need for inspection, flow-drilling can immediately be followed by thread roll-forming.

There is no need for the use of material sockers: the parent material is being usec.

Crevice and dissimilar-metal corrosion do not occur.

Using collar on the tool results in a flat mounting face Using collar on the tool results in a flat mounting face on the bush. In the case of threaded bushes

for a washer to get a gas tight connection. It is possible to produce bushes th bilnd

Threaded joints and soldered, brazed or adhered connections are of a high integrity.

There are no disturbances caused by chips (like in normal driling).

driling). direct drill/tap operations.

The economic advantages of flow-drilling depend on a variety of considerations like capital equipment costs, production times and labour involvement.

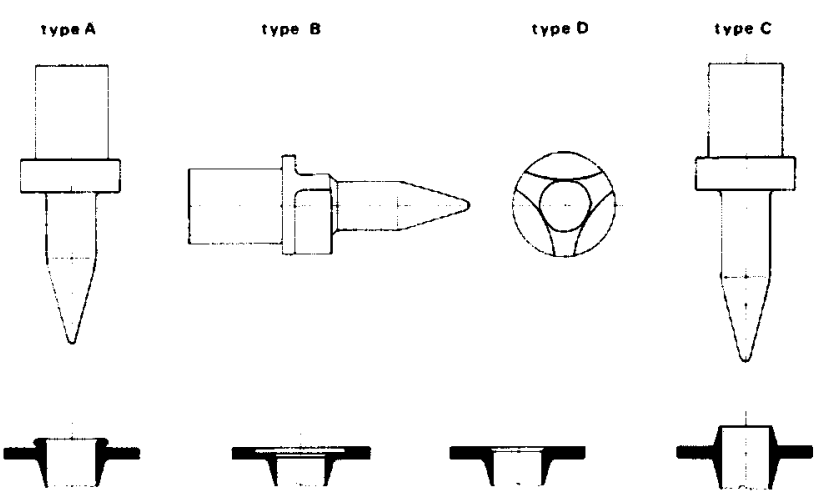


Three common avallable types of flow-drills are given in figure 2. Type A represents the standard type. Flow-drills for the bushes $B$ and $D$ are provided with cutting edges on the collar which (partiy) remove the up-wards extruded part of the bush. In the case $D$ the bush has been counterbored. The flow-drill of the type $C$ has long cylindric section to get a bush as high as possible.

The required spindle-power measures approximately four times that that needed for conventional drilling. This counts

usually applied (max.) surface speed of about holder must have a means for heat dissipation to The tool holder must have a means for heat dissipation to
prevent overhearting of the spindle-bearings. When a pressurecontrolled feed drive is used, the need for feed-rate control makes a hydraulic damped pneumatic feed-drive mechanism essential. Because of the fact that the start of the process is difficult in center ing the flow-drill, a flow-drilling machine needs a stable spindle. Bending moments on the flow-drill must be avoided because of the brittle nature of the tool material (no significant radial forces on the tool tip).

The inner diameter is very constant over the length of the bush; its value does not depend on feed-pressure and rotation speed. The outer diameter of the bush is not constant and is slightly dependent on pressure and speed. Higher pressure and higher surface speed cause the wall-thickness of the bush to increase (a few percent) [3].

In the case of asymetric products there is a tendency of noncircular bushes being formed as a result of the combined action of differenes in thermal expansion and count when as becomes asymetric within a radius of four or Eive times the diameter.

In the case of a threaded bush the strength of the comnection is even betcer than that required according to DIN-standards [4]

\section{DESCRIPTION OF THE FLOW-DRILLING PROCESS}

General. $1 \mathrm{f}$ a standard-shape flow-drill is given. Using this In figure $1 A$ a standard-shape flow-drill is given. Using this
type of flow-drili, the bush-making operation can be considered type of flow-drill, the bush-making operat
to consist of three phases, respectively:

1. The start-up: from the first contact of the tip of the flowdrill with the workpiece up to that position where the travelled distance in axial direction is equal to the material thickness $\left(z=\right.$ md $\left.=l_{1}\right)$.

2. The extrusion phase: from $z=m$ up to that position where the displacement $z$ equals $l_{1}+l_{2}+h$ (bush length)

3. Bush-calibration and collar-washering phase.

Figure 3 gives a survey of the different variables involved.

The different variables are arranged as follows:

I Independent variables

a. Workpiece and tool parameters

- Material properties of tool and workpiece

- Thickness of the workpiece material md - Diameter of the tool

$[\mathrm{mm}]$

. Free (adjustable) variables

- Feed force/feed velocity

- Rotation speed

- Surface speed

- Lubricant

$D_{t}$

$\mathrm{F}_{z} / \mathrm{V}_{z} \quad[\mathrm{~N}] /[\mathrm{m} / \mathrm{s}]$

$\begin{array}{ll}\mathrm{V}^{2} & {[\mathrm{rad} / \mathrm{s}]} \\ \left.\mathrm{s}^{3} / \mathrm{m} / \mathrm{s}\right] & \end{array}$

Dependent variables

a. Process:

- Feed velocitylfeed force

$\begin{array}{ll}\text { - Feed velocity/feed force } & \mathrm{V}_{z}, \mathrm{~F}_{z} \\ \text { - Apparent Coefficient of Frtction } & -\mathrm{M} / \mathrm{i} \\ \text { - Driving moment }\end{array}$

- Contact temperature (tool/workpiece) ${ }^{M_{z}}$

- (Specific) Energy

- (Specific) Power

- Radial forces

b. Product:

- Inner diameter of the bush

- Wall thickness of the bush

- Total height (length) of the bush

- Total height (length) of the

down-ward bush

- Total height (length) of the

up-ward bush

$\mathrm{M}_{z}$
$\mathrm{~W}_{\text {spec }}$
$\mathrm{P}$ spec

$\left[\begin{array}{l}m / s] \\ {[1]} \\ {[\mathrm{N}, \mathrm{m}]}\end{array}\right.$

$\mathrm{T} C\left[{ }^{\circ} \mathrm{C}\right]$

$\left[\mathrm{W} / \mathrm{mm}^{3}\right.$

[N]

D $[\mathrm{mm}]$

[mm ]

$h_{d}$

[mm]

$\mathrm{h}_{\mathrm{u}}$

[mm]

Measurements are carried out using a specially designed flowdrilling machine supplied with a hydraulic damped pneumatic feed-drive mechanism. In this case the feed force is adjustable.

The presently reported results concern:

$$
\begin{array}{cllllll}
\text { Diameters } & D_{t}: & 9 & 12 & 16 & \mathrm{~mm} & \\
\begin{array}{c}
\text { Material thickness md: } \\
\text { Kinds of material }
\end{array} & 2 & 3 & 4 & 5 \mathrm{~mm} & \\
\text { steel } & & \text { Mild } & \text { steel, } & \text { Alfa-brass, Stainless }
\end{array}
$$

(C20) (Cu63, Zn37) (Cr18,Ni11.5)

The experimental program has been arranged as given below.

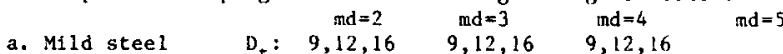

a. Mild steel $\quad D_{t}: 9,12,16 \quad 9,12,16 \quad 9,12,16$

$\begin{array}{lllll}\text { b. Alfa-brass } & D_{t}: 9,12,16 & 9,12,16 & \\ \text { c. Stainless stee1 } D_{t}: & 9,12,16 & 9,12,16 & 9,12,16\end{array}$
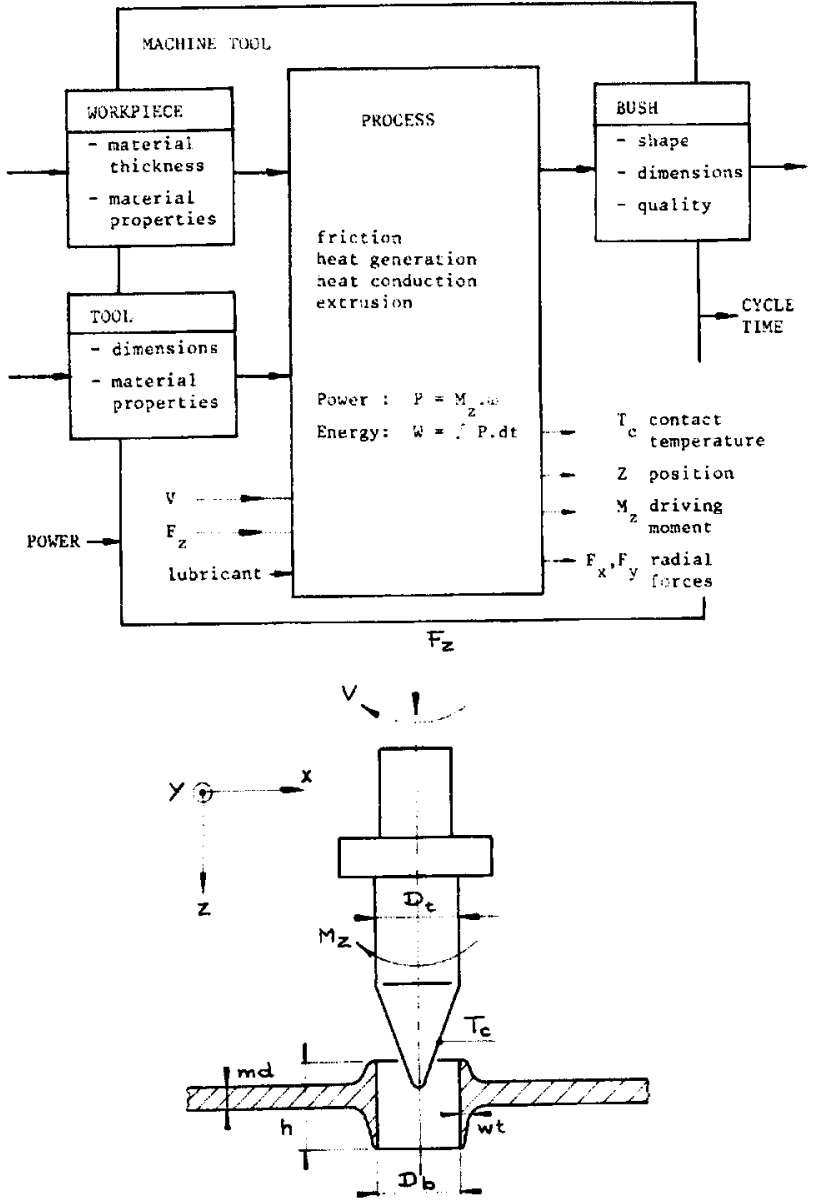

Pigure 3: System representation of the flow-drilling process.

The following variables have been recorded:

1. Feed force

2. Tool position

3. Driving inoment of the tool

4. Contact temperature

In the figures 4 and 5 the characteristics of the feed force, feed velocity, driving moment and contact temperature are plotted against the travelled distance of the flow-drill in $z-$ direction. For a better identification of the different phases of the proces, the contour of the flow-drill is drawn along the z-axis. The presented results deal with the start-up and extrusion phase only.

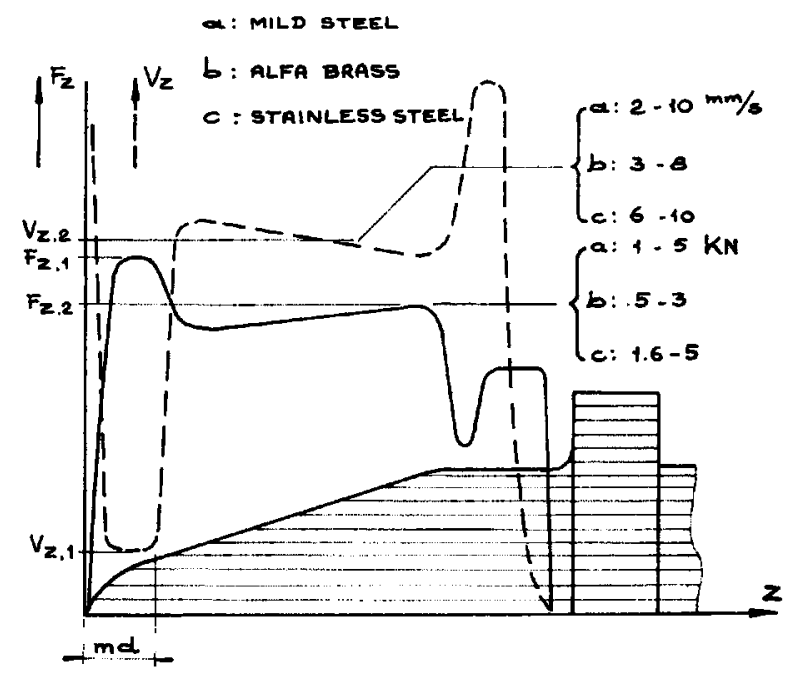

Figure 4: Feed force $F_{2}$ and feed velocity $V_{z}$ vs. $z$ for the start-up and the extrusion phase on 1 y. 


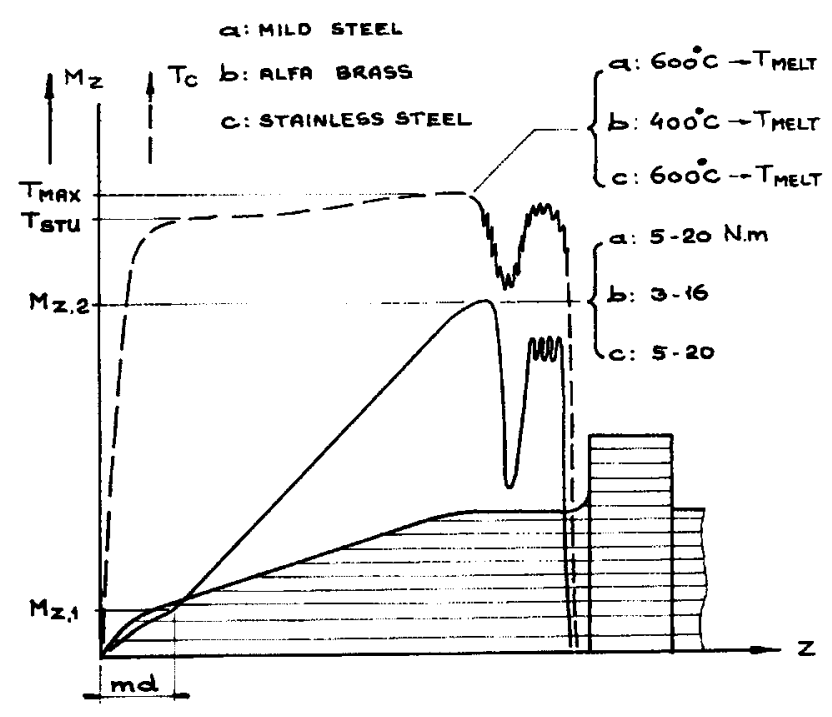
Figure 5: Friction moment $M_{2}$ and Contact Temperature $T_{c}$ vs.
$z$ for the start-up and the extrusion phase only.

At the start of the process, the feed force is built up in a very short period of time. However, both the contact surface and the surface speed between flow-drill and workpiece are very small. Despite a high contact pressure, only a low amount of small. Despite a high contact pressure, only a low amount of energy is dissipated. Below certain minimum values of $F_{2}$ and w the process will not start: The ratio of generated and
conducted heat is too low. After the start-up $(z=m d)$ the feed velocity increases significantly as a result of an increased heat generation caused by the increasing surface speed. This causes the actual feed force to decrease after the start-up because the hydraulic damper becomes more active. During the extrusion phase the feed force increases somewhat (about $5 \%$ ). This again is a result of the changing velocity of the tool in $z$-direction. When the extrusion phase is terminated $\left(z=l_{1}+1\right.$ $z$-direction. When the extrusion phase 1 s terminated $\left(z=1_{1}+1_{2}\right.$

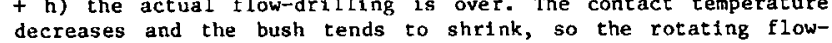
drill is being clamped and, in a way, the process is started-up again. This effect continues to work periodically for a while, during which period the surrounding material cools and shrinks and the bush is being callbrated. The increase of the feed force in this phase, as shown in figure 4, is not a result of the down-washering of the collar of the bush. During the extrusion phase, the moment of friction increases linearly with the phase, the me of cherion increases ilnearly wh the indicates that the active areas on the facets of the tool remaln equal over the length of the cone.

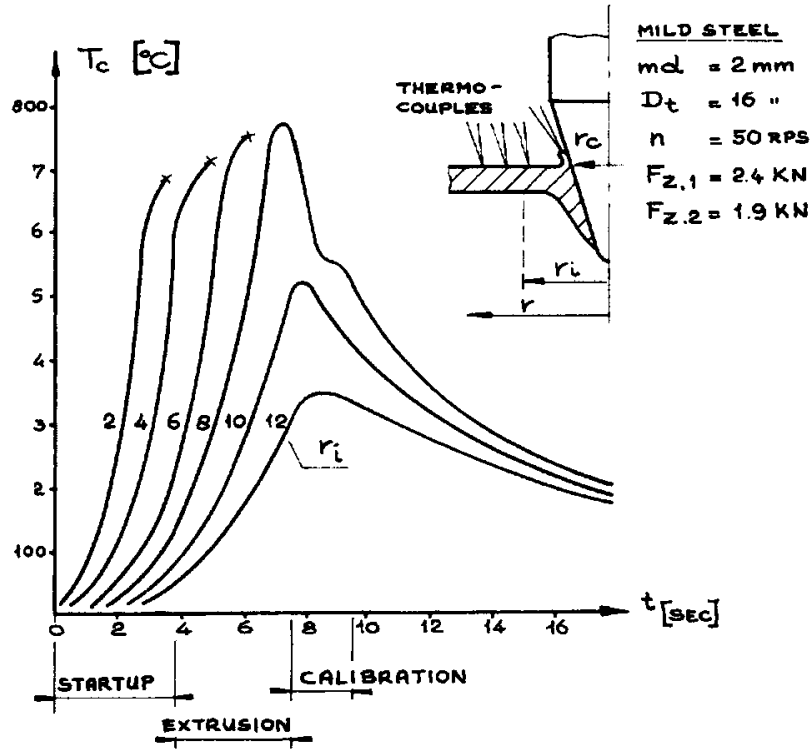

F1gure 6: Contact temperature $T_{c}$ vs. time

After the extrusion phase, initially the moment of friction decreases very strongly. But shortly after that, during calibration, it starts oscillating around a certain value, this coinciding with temperature and sound effects.

The measurement of the contact temperature is difficult since the temperature gradient $\mathrm{dT} / \mathrm{dt}>300{ }^{\circ} \mathrm{C} / \mathrm{sec}$ and $\mathrm{dT} / \mathrm{dx}>200$ ${ }^{0} \mathrm{C} / \mathrm{mm}$. Therefore, the thermo-couple method has been applied, using the teaperature/EMF relations for the carbide tool and the different values workpiece talerials. One is aware of the act that the over the contact-area between tool and workpiece. Already during the start-up of the process about $90 \%$ of the maximum recorded temperature is reached. During the extrusion phase the contact temperature rises only slightly. When calibration starts, the temperature drops suddenly but quickly recovers while oscillating somewhat below the maximun level.

Occasionally also the temperatures on the workpiece surface in the near vicinity of a growing bush have been measured. For this cr/Al thermo-couples were welded on the surface on concentric circles around the planned bush. Unfortunately the thernocouples loosen at the moment the outer diameter of the bush reaches their position. So the measured max. values (see flgure 6) can only be considered as the lower limits of the temperature in the extruding naterial.

Load characteristics of the tool. from the naterial properties of the tool, a table of influencing load factors is given below. Periodically changing thermal- and mechanical load components are causing both direct and indirect wear phenomena which are detrinental to tool life.

\begin{tabular}{l|l|l|}
\hline \multirow{3}{*}{ Direct } & \multicolumn{1}{|c|}{ Thermal load } & \multicolumn{1}{c|}{ Mechanical load } \\
\cline { 2 - 3 } & $\begin{array}{l}\text { DT } \\
\text { Thermo-Stress } \\
\text { Change of Material } \\
\text { Properties }\end{array}$ & $\begin{array}{l}\text { Mechanical Stresses } \\
\text { Abrasive Wear }\end{array}$ \\
\hline \multirow{3}{*}{ Indirect } & $\begin{array}{l}\text { Corrosion, Diffusion } \\
\text { Micro-cracks }\end{array}$ & $\begin{array}{l}\text { Forming of Micro-cracks } \\
\text { by fatigue }\end{array}$ \\
\hline
\end{tabular}

Notes to: causing thermo-stress. It is experienced that with respect to tool life, thermo-stress is dominant in flow-drilling. Dependent on the material properties, thermo-stress can directly become fatal resulting in complete breakage of the carbide flow-drill. The resistance against thermo-stress of carbide flow-drill. The resistan

$$
\begin{aligned}
& R_{T}=\text { Const. } \frac{\sigma_{f} \cdot k}{E \cdot \alpha}=\text { Const } \cdot \varepsilon_{f} \frac{k}{\alpha} \\
& \text { where: } \sigma_{f}: \text { fracture strength } \\
& \text { E: } \quad \varepsilon_{\mathrm{f}} \text { : } \text { fracture strain } \\
& \alpha: \quad \text { coefficient of thermal expansion } \\
& k \text { : coefficient of heat transfer }
\end{aligned}
$$

The formula is used for choosing the right carbide grade. An analys is made of the thermal stresses showed the need for having a boring in the tool for diameters beyond 10-12 mm [2]. For diameters beyond $20 \mathrm{~mm}$ the size of the collar graduatly becoming the main limiting factor in tool life.

IT: Just like diffusion, corrosion of the tool material becomes an important problem in flow-driling where temperatures close to the melting point of the workpiece material are readily possible. Experiments carried out with some $K-10$ grade on mild steel resulted in a quick detoriation of the surface of the tool by oxidation. This was followed by growing (micro)-cracks and these tools came to a total breakage within 80-350 bushes. The use of a TIC-TiN coating solved the oxidation problem but then a lack of hot-hardness caused plastic torsion of the cone and finally total caused plastic torsion of the cone and finally total
breakage at nearly 1000 bushes (about $15 \%$ of normal tool life) [2].

DM: The mechanical load on the tool primarily consists of an axial feed force and a torsion moment. To give an idea of the order of magnitude: With a diameter of $12 \mathrm{~mm}$ and an axial force of $4 \mathrm{kN}$ the normal stress on the facets of the tool is estimated to be $360 \mathrm{~N} / \mathrm{mm}^{2}$ while the corresponding tangential stress is $105 \mathrm{~N} / \mathrm{mm}^{2}$. (An estimate is made of the actual length of engagement of the facets). Reference made to the transfer rupture strength of about $2000 \mathrm{~N} / \mathrm{mm}^{2}$ yields that on the basis of these values, fracture can hardly be expected. The tool-tip gradually becomes blunt by abrasive wear. Worn facets are not directly playing a significant part in tool life since total breakage occurs before the limiting tolerances of the diameter are exceeded. However, experiments have shown that the contact-temperature will $r$ ise about $10 \%$ by this. So tool $11 \mathrm{fe}$ will be influenced. Flow-drilling in the case of a workpiece with a corroded surface proves to be very dangerous for the tool. It is believed that severe centration problems as a result of delayed start-up are responsible for this. The quickly increasing feed force causes significant radial forces by which total breakage is to be expected (within a few bushes).

IY: Up till now it was not possible to indicate any significant inf luence. 
Temperatures

From the measured EMF-values it follows that the average contact-temperature $T_{c}$ is almost independent of the feed force $F_{2}$. The inflience of the surface speed on $T_{c}$ is depicted in ifg. 7 .

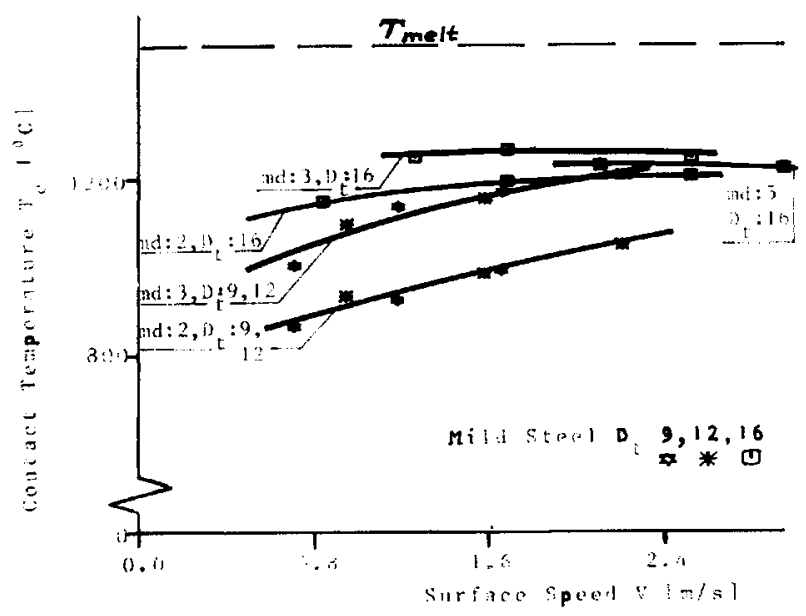

Figure 7: Contact temperature $T_{c}$ vs. Surface Speed $V$.

The graph shows an asymptotic behaviour, the maximum of $T_{c}$ stabilizing when approaching $0,85 \mathrm{~T}$ (melting point) the influence of the diameter of the tool (apart from the surface speed) and the material thickness can for the greater part be explained by a coherent increase in the active flow-driling time (see also fig. (D). It is quite possible that the measuring time (see also fig. 10 ). It is quite possible that the measuring
nethod in itself is also partly responsible for the observed influences of material thickness and tool diameter. The conclusion that, for the usual applied surface speed of $1.5 \mathrm{~m} / \mathrm{s}$, the larger flow-drills are subjected to a significantly higher thermal load seems to be justified. This is confirmed by two facts:

1. Tool life decreases with the increasing diameter of the tool.

2. Observations show that the colour of a $16 \mathrm{~mm}$ tool may easily become bright-yellow while the smaller tools perform perceptibly cooler.

A remark should be made regarding the fact that in an automated environment the $T$-values of the smaller sized tools may shift somewhat towards figher numbers, this being the result of less cooling time.

For given process-conditions the temperature $T_{c}$ is doninated by the shear-stress/temperature relation belonging to the applied workpiece material. When the surface speed is increased, the subsequent temperature rise will be limited. This happens as a result of the amount of energy which can be dissipated being limited by a drop in the shear-stress. The temperature will early stabilize at a point where both the supplied energy and the admisstble energy are in equilibrium. This behaviour is indicated in $\mathrm{f}$ ig. 8 showing the curves representing the apparent coefficient of $\mathrm{riction}$ between tool and workpiece as function of $T$. This also explains why, within the feasible working of ${ }^{T}{ }^{c}$. This also explains why, within the feasible working
range, the extrusion speed during bush formation is not range, the extrusion speed during bush

Tool life.

The number of bushes which can be made with one tool amounts from a few thousands for the larger sizes and for stainless steel to virtual infinicy (for the smaller sizes and for copper). The main factors which are considered to determine tool life are:

- surface speed

- material properties of the tool

tool size

material properties of the workpiece

material thickness

surface integrity of the workpiece

lubrication

Since tool-life tests are very time-consuming and extremely costly, no laboratory life-test have been carried out. The limited number of results presented in this section are calculated from data which are collected in industrial workshops. Thet $r$ validity is limited in the sense that they are related to:

An approximate surface speed of $1.5 \mathrm{~m} / \mathrm{s}$

different non-specifled values of the material thickness

non-standardized lubrication conditions

different non-specified low-carbon steels

The evaluation carried out with the aid of the Weibull fxtreme
Value Theory seems to be justified since the value of the calculated correlation factor in each case proves to be fair. The results presented below apply to a P25 carbide grade.

Experience gained over a long period of time shows that in the case of low-carbon steels and for diameters $<10 \mathrm{~mm}$, tool life easily exceeds 20.000 bushes. In all cases, tool life is deternined by fatal rupturing or total breakage. Cases in which a tool had to be changed becallse of intolerable wear on the calibration part, are not known.

The influence both of the material properties of the tool and of the surface integrity of the workpiece on tool life has been diacussed in the previous paragraph. The dominating influence of thermo-stress makes it possible to give a rough estimate of the influence of the workpiece material on tool life: A low melting- point and a quickly dropping shear-stress/temperature curve will result in favourable machining characteristics and promote a long tool life.

\begin{tabular}{|c|c|c|c|}
\hline Diameter & 12 & 15 & 19 \\
\hline Nunber of specimen & 23 & 6 & 10 \\
\hline $\begin{array}{l}\text { Characteristic Weib } \\
\qquad \begin{array}{l}P_{0} .632 \\
\text { slope m }\end{array}\end{array}$ & $\begin{array}{c}11 \text { va lues } \\
11.882 \\
5.7\end{array}$ & $\begin{array}{r}12.194 \\
5.36\end{array}$ & $\begin{array}{r}10.148 \\
5.05 \\
\end{array}$ \\
\hline Correlation $r^{2}$ & 0.83 & 0.93 & 0.99 \\
\hline $\mathrm{T}_{50 \%}$ & 11.900 & 11.388 & 9.437 \\
\hline T $90 \%$ & - & 8.014 & 6.498 \\
\hline T $95 \%$ & 7.000 & 7.007 & 5.635 \\
\hline
\end{tabular}

T $90 \%=$ Tool life will be reached by probably $90 \%$ of the

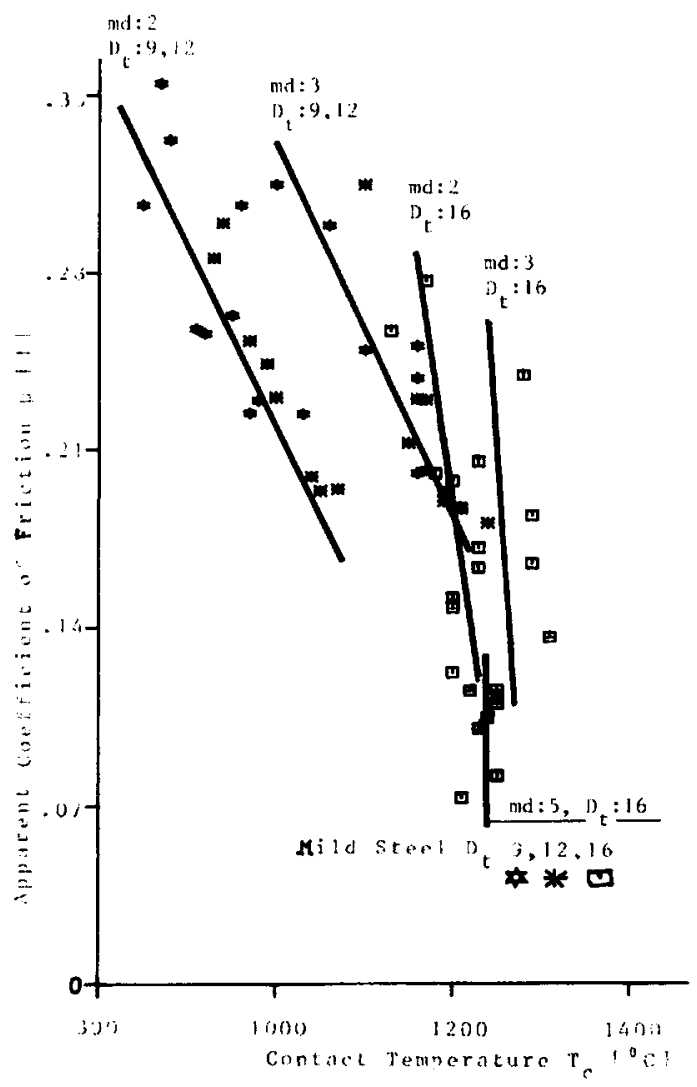

Figure 8: Apparent Coefficient of Friction vs. Contact Temperature $\mathrm{T}_{\mathrm{C}}$. 


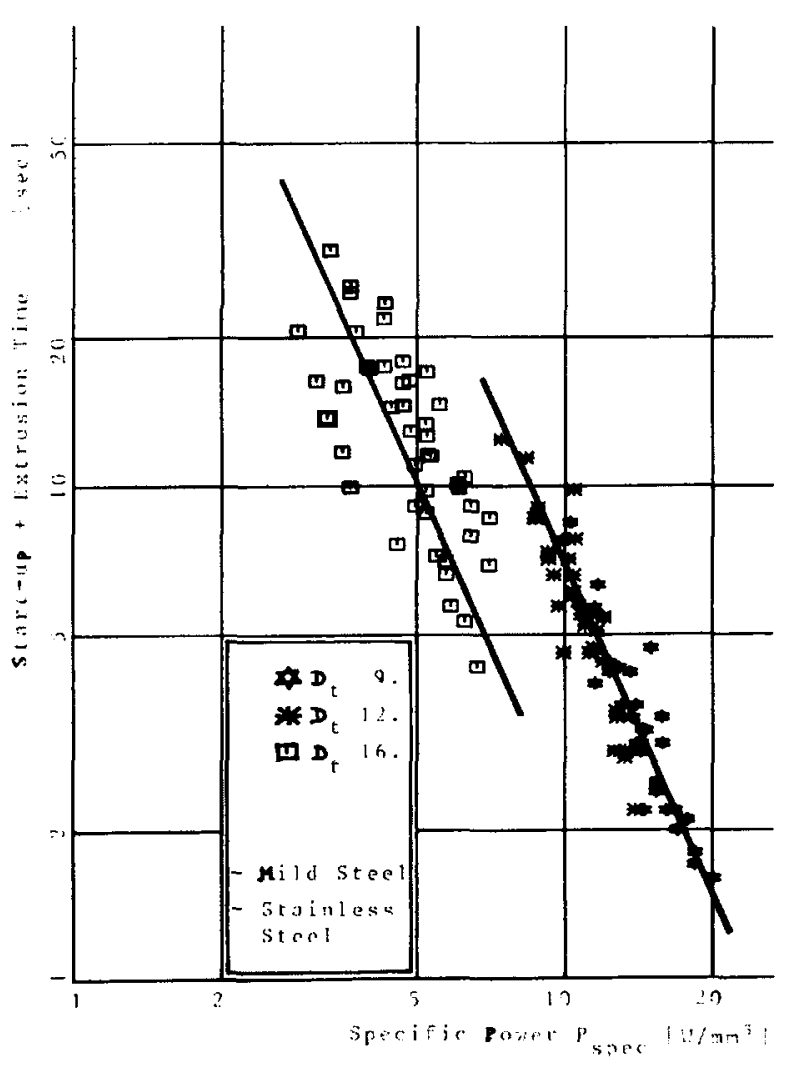

Fig. 9 Operation (Start-up + Extrusion) Time us. Specific Power

Operation-Times

The recorded flow-drilling times anount from a few to about 25 seconds. Fig. 9 shows the results as depleted in relation to the required specific power. (The washering-down phase is excluded.) The differentiation between the $16 \mathrm{~mm}$ tool and the others disappears when only the extruston phase is taken into account (fis 10$)$. The time which is needed to start up changes from (fig. 10). The time which is needed co start up changes from about i second ( $9 \mathrm{~mm}$ ) to about 10 seconds ( $16 \mathrm{~mm})$.

Fig. In shows that the numbers representing the extrusion time can be arranged to flt one single curve, regardless of the type of steel and service speed. It yields from fig. 10 also that the required specific power decreases with increasing size of the tools. This behaviour complies with metal cutting where the specific energy decreases with increasing feed. Bauer and Kretschmer [7] reported $26 \mathrm{~W} / \mathrm{mm}^{3}$ for a $7 \mathrm{~mm}$ tool which is quite in agreement with the present findings.

REMARKS

- Attempts have been ade to carry out a thorough dimensional analysi.s of the process but the results have been disappointing up till now.

- Both the present available results and the required data are urgently inviting continued research.

rlow-drills are brought on the market by

Flowdrill BV, Utrecht, Netherlands.

Drabus BV, Apeldoorn, Netherlands.

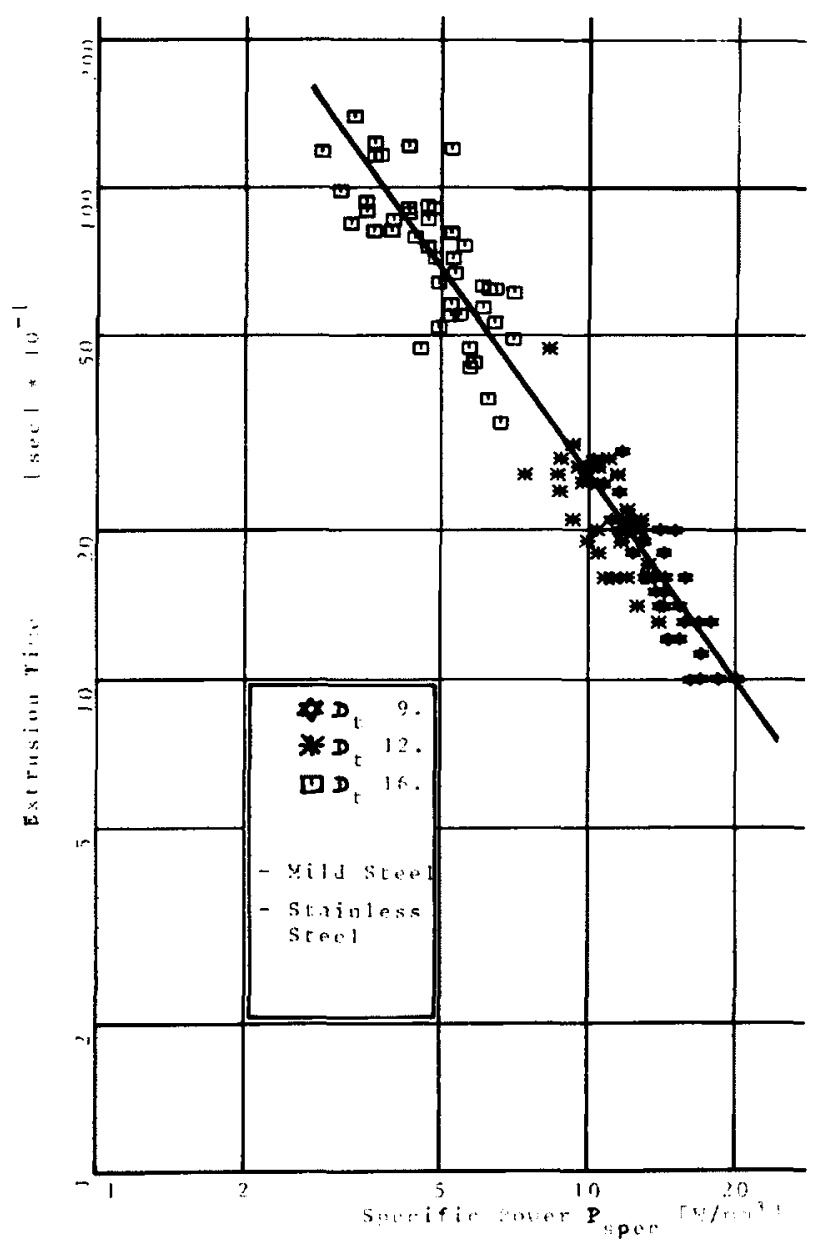

Fig. 10 fextrusion Time vs. Specific Power.

REFERENCES

[1] Anonymous, flow-drilling. A method of forning integral artachment bushes in thin steel, Machinery, (1975).

[2] Kals, H.J.J., The developinent of Flow-drills with a diameter of 12 to $25 \mathrm{~mm}$ (in Dutch), Reports, aug. 1977 and nov. 1977.

[3] Kretschmer, G., Flieslochformen, wt.\%.f.ind.Fertig., $67(1977), 667-669$.

[4] Kretschmer, G., Die Technologie des Fliesslochformens, VDIBerichte, 330 (1978).

[5] Kals, H.J.J., Fliessbohren: Ein neuartiges Verfahren für die Spanlose Fertigung von Durchzïgen, voI-Berichte, 330 (1978).

Kals, H..l.J., Vloefboren. Metaalbewerking 22 (1978), 250253.

(6) Overy, K., Flow-drilling - bush formation in thin thetal, CME, $70(1978)$

[7] Baver, D., und Kretschmer, G., Umformarbeit bein Fllesslochformen, wt. .. f.ind. Fertig., 72 (1982), 451-454.

LITERATURE

1 Braicen, P.M., The Cal ibration of the Tool-Work Thermocouple, Proc. of the 8th intern. MTDR-Conf., (1967).

2 Veenstra, P.C., e.a. Thermo-electric Characteristics of Carbides, Annals of the CIRP, Vol. 20/1 (1971).

3 Barrow, G., A Review of Experimental and Theoretical Techniques for Assessing Cutting Temparatures, Annals of the CIRP, Vol. 22/2 (1973). 